\title{
Biofilm formation by a Bacillus subtilis strain that produces $\gamma$-polyglutamate
}

\begin{abstract}
Correspondence
Masaaki Morikawa

morikawa@ees.hokudai.ac.jp
\end{abstract}

Received 12 April 2006

Revised 19 May 2006

Accepted 12 June 2006

\author{
Masaaki Morikawa, ${ }^{1,2} \uparrow$ Shinji Kagihiro, ${ }^{1}$ Mitsuru Haruki, ${ }^{1} \ddagger$ \\ Kazufumi Takano, ${ }^{1}$ Steve Branda, ${ }^{2}$ Roberto Kolter ${ }^{2}$ and Shigenori Kanaya ${ }^{1}$ \\ ${ }^{1}$ Department of Material and Life Science, Graduate School of Engineering, Osaka University, \\ Osaka 565-0871, Japan \\ ${ }^{2}$ Department of Microbiology and Molecular Genetics, Harvard Medical School, Boston, MA \\ 02115, USA
}

\begin{abstract}
The extracellular matrix produced by Bacillus subtilis B-1, an environmental strain that forms robust floating biofilms, was purified, and determined to be composed predominantly of $\gamma$-polyglutamate $(\gamma$-PGA), with a molecular mass of over $1000 \mathrm{kDa}$. Both biofilm formation and $\gamma$-PGA production by $B$. subtilis $\mathrm{B}-1$ increased with increasing $\mathrm{Mn}^{2+}$ or glycerol concentration. $\gamma$-PGA was produced in a growth-associated manner in standing culture, and floating biofilms were formed. However, $\gamma$-PGA was produced in a non-growth-associated manner in shaking culture conditions. When $B$. subtilis B-1 was grown in a microaerated culture system, floating biofilm formation and $\gamma$-PGA production were significantly retarded, suggesting that oxygen depletion is involved in the initial steps of floating biofilm formation in standing culture. Proteomic analysis of membrane proteins demonstrated that flagellin, oligopeptide permease and Vpr protease precursor were the major proteins produced by cells in a floating biofilm and a colony.
\end{abstract}

\section{INTRODUCTION}

Biofilms are surface-attached communities of bacteria embedded in an extracellular matrix. Biofilm formation occurs in many settings, and in response to diverse environmental cues (O'Toole et al., 2000; Parsek \& Greenberg, 2005). For example, biofilms can form over solid surfaces, or at the surface of liquids. In the latter case, the floating biofilms are referred to as pellicles. The colonies that grow on semi-solid media can also be considered to be a form of biofilm. Macroscopic and microscopic observations of bacterial biofilms reveal highly ordered structural features that disappear when the components of the extracellular matrix are eliminated as a consequence of mutation (Branda et al., 2005).

The extracellular matrix contributes to the mechanical stability of the biofilm, enabling it to withstand considerable shear forces, and the biofilm has been shown to contain

†Present address: Division of Biosphere Science, Graduate School of Environmental Science, Hokkaido University, Sapporo 060-0810, Japan.

‡Present address: Department of Materials Chemistry and Engineering, College of Engineering, Nihon University, Koriyama, Fukushima 9638642, Japan.

Abbreviations: CSF, competence-stimulating factor; CV, crystal violet; EPS, exopolysaccharide; HPTLC, high-performance silica gel thin layer chromatography; MACS, microaerated culture system; $\gamma$-PGA, $\gamma$ polyglutamate; SEM, scanning electron microscopy. polysaccharides, proteins and nucleic acids (Branda et al., 2005). Among the polysaccharides present in the biofilm matrix are: alginate, Pel and Psl in Pseudomonas aeruginosa; cellulose in Escherichia coli and Salmonella typhimurium; a tetrasaccharide repeat of D-glucose, L-fucose and Dglucuronic acid in Klebsiella pneumoniae and Enterobacter aerogenes; gellan in Sphingomonas spp.; and levan ( $\beta$-Dfructan) in streptococci (Boyd \& Chakrabarty, 1995; Danese et al., 2000; Friedman \& Kolter, 2004; Kiska \& Macrina, 1994; O’Neill et al., 1986; Yamazaki et al., 1996). The matrix from Vibrio cholerae $\mathrm{O} 1$ biofilms has been shown to contain a polysaccharide composed of $N$-acetyl-D-glucosamine, Dmannose, 6-deoxy-D-galactose and D-galactose (Wai et al., 1998).

In recent years, Bacillus subtilis, a spore-forming Grampositive bacterium, has become a model organism for the study of biofilm formation (Branda et al., 2001; Hamon \& Lazazzera, 2001). It has been shown that wild strains of $B$. subtilis generally form more robust floating biofilms than strains derived from the domesticated laboratory strain $B$. subtilis 168 . In the highly structured floating biofilms and colonies formed by the wild strain B. subtilis 3610, sporulation displays a high degree of spatio-temporal organization, occurring predominantly at the tips of aerial projections. This confirms that biofilm formation can be an integral part of the developmental processes of this organism. For B. subtilis 3610, a major component of the extracellular matrix in colonies and floating biofilms is the 
putative exopolysaccharide (EPS) produced by the eps locus (Branda et al., 2001, 2005; Kearns et al., 2005). However, the macroscopic features of colonies and floating biofilms formed by different wild strains of $B$. subtilis can be dramatically different. Such was the case when we compared B. subtilis 3610 with B. subtilis B-1, which is an environmental strain isolated from an oilfield (Morikawa et al., 1992). Here, we report that $\gamma$-polyglutamate $(\gamma$-PGA) is a major extracellular polymeric substance, and that oxygen depletion is an important signal for floating biofilm formation in B. subtilis B-1. We also demonstrate that flagellin, oligopeptide permease and Vpr protease precursor are the major membrane proteins produced in floating biofilm cells.

\section{METHODS}

Culture media. Luria (L-) broth, containing $\left(1^{-1}\right) 10$ g Bacto tryptone (Difco), $5 \mathrm{~g}$ yeast extract (Difco) and $10 \mathrm{~g} \mathrm{NaCl}$, was used for general cultivation of bacteria. L-agar is a semi-solid medium containing $1.2 \%$ agar in L-broth. E-medium is a medium used for effective production of $\gamma$-PGA (Cromwick \& Gross, 1995), and it contains $\left(1^{-1}\right)$ : $20 \mathrm{~g}$ L-glutamic acid, $12 \mathrm{~g}$ citric acid, $80 \mathrm{~g}$ glycerol, $7 \mathrm{~g} \mathrm{NH}_{4} \mathrm{Cl}, 0.5 \mathrm{~g} \mathrm{MgSO}_{4} .7 \mathrm{H}_{2} \mathrm{O}, 0.5 \mathrm{~g} \mathrm{~K}_{2} \mathrm{HPO}_{4}, 0.15 \mathrm{~g} \mathrm{CaCl}_{2} .2 \mathrm{H}_{2} \mathrm{O}$, $40 \mathrm{mg} \mathrm{FeCl} 3 \cdot 6 \mathrm{H}_{2} \mathrm{O}$ and $148 \mathrm{mg} \mathrm{MnSO}_{4} \cdot \mathrm{H}_{2} \mathrm{O}$. The $\mathrm{pH}$ of E-medium was adjusted to $7 \cdot 4$ by $2 \mathrm{M} \mathrm{NaOH}$. The amounts of glycerol and $\mathrm{MnSO}_{4}$ were adjusted as noted.

Scanning electron microscopy (SEM). Pellicles were gently placed on a glass plate that had been coated with poly-L-lysine. The specimen was fixed with glutaraldehyde and $\mathrm{OsO}_{4}$, dehydrated in ethanol, isoamyl acetate and critical $\mathrm{CO}_{2}$, and sputter coated with platinum (Glauert, 1975). Observations were performed with a Hitachi S800 scanning electron microscope.

Preparation and analyses of extracellular matrix. B. subtilis B1 (Morikawa et al., 1992) cells were grown overnight on L-agar, and the colonies were scraped off, and suspended in $0.9 \% \mathrm{NaCl}$. This enabled us to obtain almost pure extracellular polymeric substances by a simple two-step process: removal of cells by centrifugation (30 $000 \mathrm{~g}$ at $4{ }^{\circ} \mathrm{C}$ for $30 \mathrm{~min}$ ), and ethanol precipitation by addition of 3 vols cold ethanol to the supernatant. The ethanol precipitation step was repeated twice, and the resulting material was dried in a vacuum.

A portion of the purified material was hydrolysed in $5 \mathrm{M} \mathrm{HCl}$ at $100{ }^{\circ} \mathrm{C}$ for $24 \mathrm{~h}$, and the products were separated on a silica gel 60 highperformance silica gel thin layer chromatography (HPTLC) plate (no. 05631; Merck), with a developing solvent mixture of ethanol/water (63:37). The remaining material was dissolved in $\mathrm{D}_{2} \mathrm{O}(4 \%, \mathrm{w} / \mathrm{v})$, and analysed by ${ }^{1} \mathrm{H}-\mathrm{NMR}$ and ${ }^{13} \mathrm{C}$-NMR (UNITY-INIVA 600; Brucker). These analyses revealed that the recovered material consisted almost exclusively of $\gamma$-PGA. The DL configuration of the constituent glutamic acids was determined by reverse-phase HPLC analysis, after derivatization with Marfey's reagent $\left(1 \%, \mathrm{w} / \mathrm{v}\right.$, in acetone) at $40{ }^{\circ} \mathrm{C}$ for $90 \mathrm{~min}$. The HPLC column was a COSMOSIL 5C18-AR (i.d. $4 \cdot 6 \mathrm{~mm}$, length $20 \mathrm{~cm}$; Nacalai Tesque), and the eluent was methanol $/ 20 \mathrm{mM}$ sodium acetate buffer $(\mathrm{pH} 4)$ /acetonitrile $(2: 7: 1)$. Fractions were monitored by absorbance at $340 \mathrm{~nm}$. Elution positions and the areas of the peaks were compared with standard D-glutamic acid and L-glutamic acid.

Molecular mass was determined by TSKgel G4000SWxL gel filtration chromatography (i.d. $7 \cdot 8 \mathrm{~mm}$, length $30 \mathrm{~cm}$; Tosoh), with $0.2 \mathrm{M}$ sodium phosphate buffer ( $\mathrm{pH} 6.9$ ) and $0.2 \mathrm{M} \mathrm{Na}_{2} \mathrm{SO}_{4}$. Elution of $\gamma$ PGA was monitored by absorbance at $220 \mathrm{~nm}$. The level of production of $\gamma$-PGA in the culture was estimated by comparing the peak area in gel filtration chromatography with those of the standards, or by weighing the dry material after purification.

Biofilm assays. Solid-surface-associated biofilm formation was estimated by the crystal violet (CV) staining method, with slight modifications (O'Toole et al., 1999). Briefly, an overnight culture was diluted to an $\mathrm{OD}_{600}$ of $0 \cdot 3$, and $1 \mu \mathrm{l}$ was added to $99 \mu \mathrm{l} \mathrm{E}$ medium in a 96-well plastic titre plate. The plate was kept standing at $37^{\circ} \mathrm{C}$ for $8 \mathrm{~h}$. Then, the surface pellicles and the cultures were carefully removed from the wells. Each well was gently rinsed twice with distilled water, and the remaining cells and matrices were stained with $150 \mu \mathrm{l}$ of a $1 \% \mathrm{CV}$ solution for $25 \mathrm{~min}$ at room temperature. After washing twice with distilled water, the $\mathrm{CV}$ attached to the biofilm was solubilized in $150 \mu \mathrm{l}$ DMSO, and quantified by measuring its absorbance at $570 \mathrm{~nm}$.

Preparation and analyses of membrane proteins. Cells were harvested, and washed and suspended in $10 \mathrm{mM}$ phosphate buffer $(\mathrm{pH} 7 \cdot 0)$, after growing in standing, shaking or agar culture for $14 \mathrm{~h}$ at $37^{\circ} \mathrm{C}$. In the standing culture, cells formed floating biofilms on the surface (Fig. 1). Cell suspensions were subjected to lysozyme treatment $\left(1 \mathrm{mg} \mathrm{ml}^{-1}\right)$ for $3 \mathrm{~h}$ at $37^{\circ} \mathrm{C}$, followed by sonication for $1 \mathrm{~min}$ on ice. After removing intact cells by centrifugation at $8000 \mathrm{~g}$ for $10 \mathrm{~min}$, the supernatant was further fractionated by ultracentrifugation at $90000 \mathrm{~g}$ for $1 \mathrm{~h}$. The supernatant and precipitate were used as cytoplasmic and membrane protein samples, respectively. The membrane protein samples were separated on $12 \%$ polyacrylamide gel containing $1 \%$ SDS. Protein bands were visualized by Coomassie brilliant blue R-250 staining. The gel containing a protein band was subjected to trypsin digestion, followed by amino acid sequence analysis with LC-MS/MS (Taplin Biological Mass Spectrometry Facility, Harvard Medical School, Boston, MA, USA) and Sequest (Thermo Electron).

\section{RESULTS AND DISCUSSION}

\section{Chemical structure of the extracellular polymeric substance produced by $B$. subtilis B-1}

B. subtilis B-1, which was isolated from an oilfield, was found to form robust pellicles (floating biofilms) and solidsurface-associated biofilms in standing culture. It also formed highly structured colonies on L-agar medium that were strikingly mucoid in their centre (Fig. 1). In contrast, B. subtilis 168 formed flat colonies, and did not form significant pellicles or solid-surface-associated biofilms in Lbroth. SEM observation of the pellicle produced by $B$. subtilis B-1 showed that the cells were densely packed side by side, and embedded in a matrix (Fig. 2). The $16 \mathrm{~S}$ rRNA gene sequence of $B$. subtilis B-1 (EMBL/GenBank/DDBJ accession number AB213262) is $99.6 \%$ identical to that of B. subtilis 168.

The extracellular polymeric substances produced by the colonies of $B$. subtilis B-1 were purified by ethanol precipitation, and found to yield negative results for both uronic acid and anthrone assays, suggesting that the material did not contain significant amounts of polysaccharide (May \& Chakrabarty, 1994). In addition, the purified material did not contain significant amounts of protein or nucleic acid, as evidenced by the lack of absorbance at 280 and $254 \mathrm{~nm}$. When the sample was hydrolysed, separated using HPTLC, 

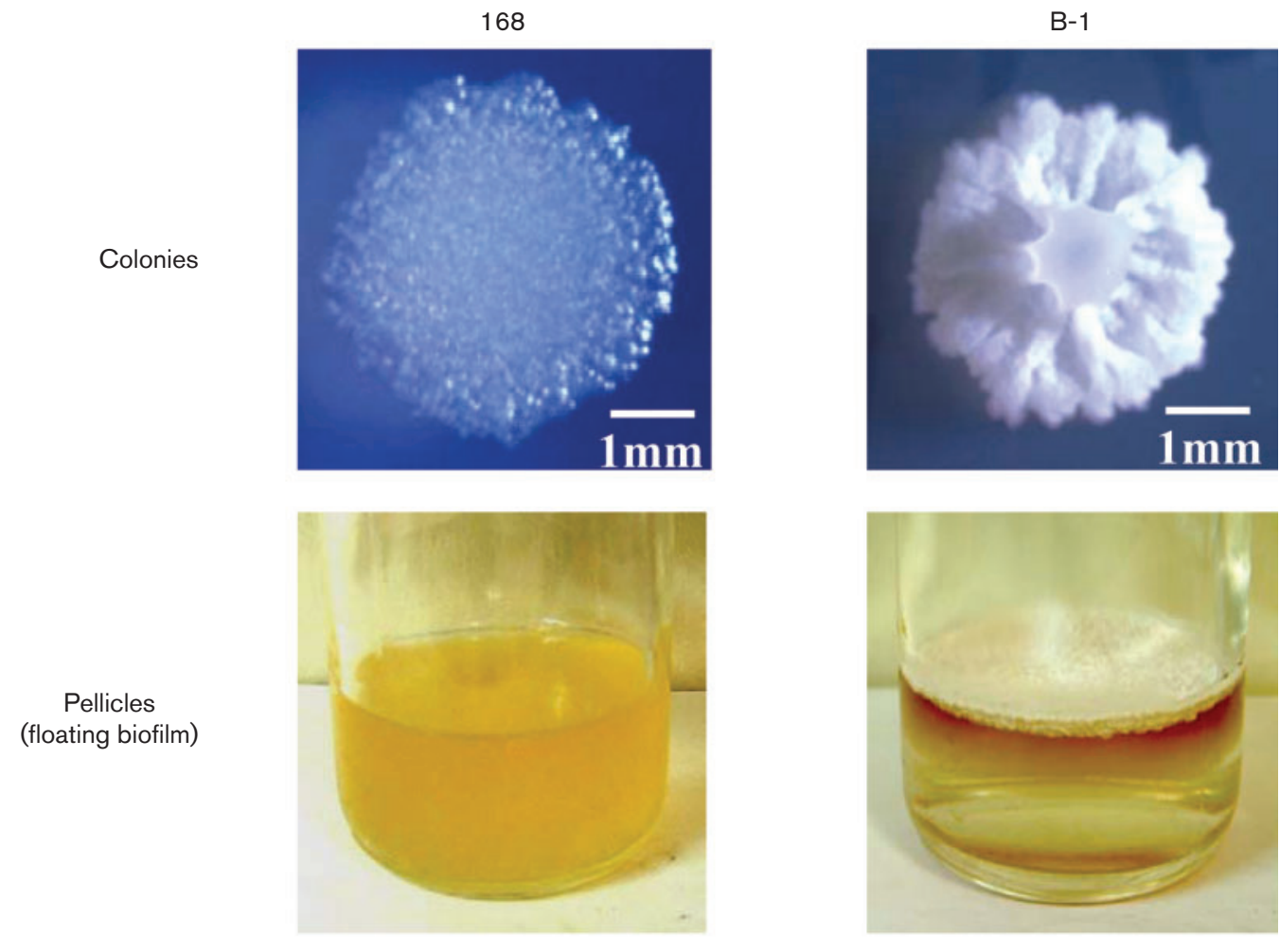

Biofilms with CV staining
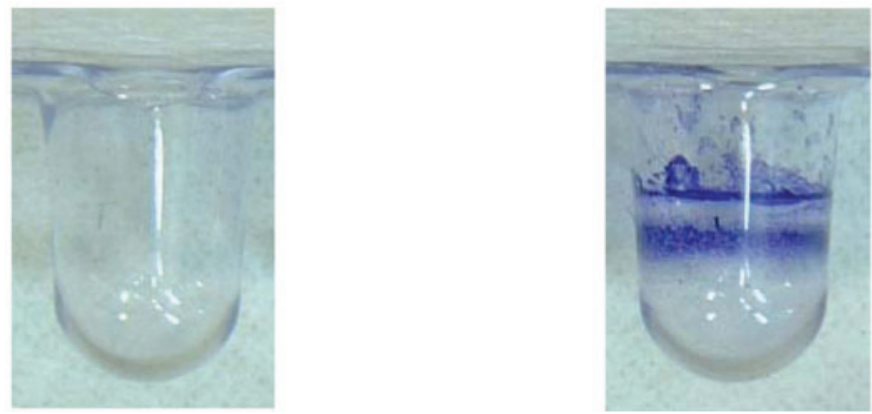

Fig. 1. Comparison of $B$. subtilis 168 (laboratory strain) and B. subtilis B-1 (environmental strain). Cells were grown on Lagar (colonies) and L-broth (pellicles, biofilms) at $37^{\circ} \mathrm{C}$ for $14 \mathrm{~h}$. Cells were taken by toothpick, and stabbed on L-agar to form a colony. Overnight liquid culture was added (1\%) to L-broth for pellicle formation, which was visualized by CV staining (see Methods).

and stained by spraying with $0 \cdot 1 \%$ ninhydrin ethanol solution, followed by baking at $100^{\circ} \mathrm{C}$, a single red-coloured spot was observed at a position corresponding to that of glutamic acid. The material was then analysed by ${ }^{1} \mathrm{H}-$ and ${ }^{13} \mathrm{C}-\mathrm{NMR}$. Chemical shifts of the peaks are shown in Table 1. All of these results indicate that the material we isolated was composed mostly of $\gamma$-PGA. Relative glutamic acid peak areas, after separation using HPLC, indicated that the ratio of D- and L-glutamic acid, constituting the $\gamma$-PGA, ranged from $9: 1$ to $4: 1$ after $12 \mathrm{~h}$ cultivation at $37^{\circ} \mathrm{C}$ in Lbroth. The molecular mass of the isolated $\gamma$-PGA was determined to be over $1000 \mathrm{kDa}$ by gel filtration chromatography. It should be noted that B. subtilis 3610 did not produce $\gamma$-PGA.

\section{Production of $\gamma$-PGA, and biofilm formation}

Recently, Stanley \& Lazazzera (2005) have reported that following transfer of the genetic determinants controlling $\gamma$ PGA formation from a wild strain to the domestic B. subtilis 168 , the latter is able to produce biofilms. However, deletion of $y w s C$, a gene encoding $\gamma$-PGA synthesis, in the wild $B$. subtilis RO-FF-1 does not to lead to a marked decrease in surface-associated biofilm formation. This result demonstrates that the production of $\gamma$-PGA is not essential for biofilm formation by $B$. subtilis. As a result of this, we were interested in determining if there was a correlation between $\gamma$-PGA production and biofilm formation in $B$. subtilis B-1. Reports by others have shown that changes in 


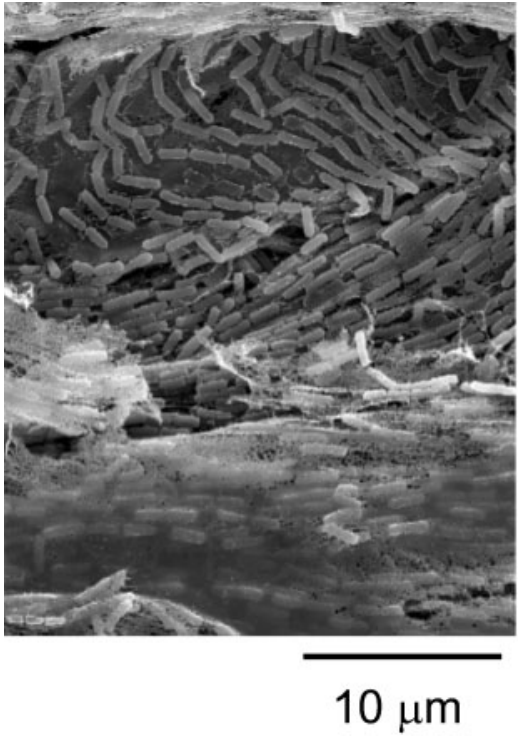

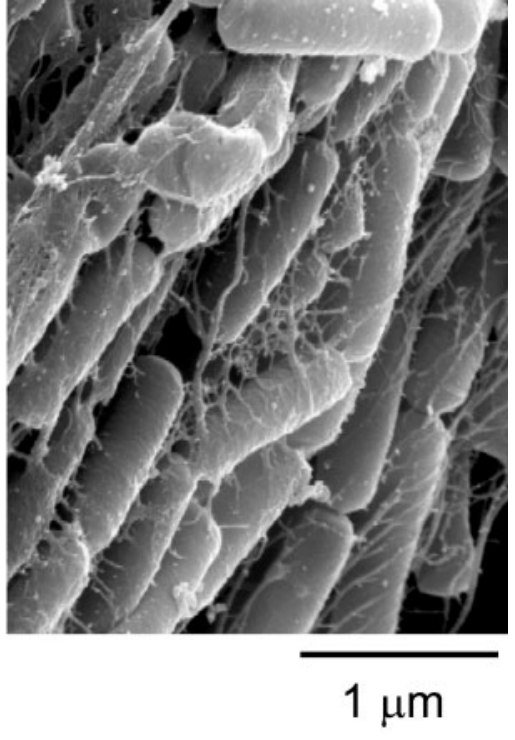

Fig. 2. SEM of pellicles formed by B. subtilis $\mathrm{B}-1$. the concentration of $\mathrm{MnSO}_{4}$ and glycerol affect $\gamma$-PGA production by Bacillus licheniformis ATCC 9945A (Cromwick \& Gross, 1995; Ko \& Gross, 1998). We found similar results for B. subtilis B-1 (Fig. 3a, b). Importantly, this allowed us to show that there was a direct correlation between $\gamma$-PGA production and biofilm formation in $B$. subtilis B-1 (Fig. 3c). This correlation also held for another B. subtilis strain, B. subtilis natto BEST 195, which is a moderate $\gamma$-PGA producer (data not shown; Itaya \& Matsui, 1999). We cloned the $y w s C$ gene from $B$. subtilis B-1, and tried to generate a B-1-derived $y w s C$ knockout mutant, but we were unable to do this.

In order to examine whether pellicle formation is a cause or a result of $\gamma$-PGA production, growth kinetics and $\gamma$-PGA production by B. subtilis B-1 were compared in standing and shaking culture. The cells did not form pellicles in the shaking culture because of the continuous shear stress. Production of $\gamma$-PGA in standing culture started $6 \mathrm{~h}$ after inoculation, when pellicle formation had not yet started. Moreover, $\gamma$-PGA was produced in the shaking culture, albeit after a significant lag, about $12 \mathrm{~h}$ after inoculation (Fig. 4). Eventually, after $24 \mathrm{~h}$, the levels of $\gamma$-PGA produced were similar in standing and shaking culture. These results

Table 1. Chemical shift values of NMR analyses of EPS from $B$. subtilis B-1

\begin{tabular}{|lcc|}
\hline Peak & ${ }^{1}$ H-NMR $(\boldsymbol{\delta}=$ p.p.m. $)$ & ${ }^{13}$ C-NMR $(\boldsymbol{\delta}=$ p.p.m. $)$ \\
\hline$\alpha-\mathrm{CH}$ & $4 \cdot 19$ & $55 \cdot 44$ \\
$\beta-\mathrm{CH}_{2}$ & $2 \cdot 08,1 \cdot 93$ & $28 \cdot 34$ \\
$\gamma-\mathrm{CH}_{2}$ & $2 \cdot 34$ & $32 \cdot 89$ \\
$\mathrm{CO}$ & - & $175 \cdot 53$ \\
$\mathrm{COOH}$ & - & $178 \cdot 90$ \\
\hline
\end{tabular}

indicate that pellicle formation is not a requirement for $\gamma$ PGA production in $\mathrm{B}-1$.

\section{Depletion of dissolved oxygen, and biofilm formation}

It is known that vigorous aeration is effective for high $\gamma$-PGA yields (Cromwick et al., 1996). In order to test the effect of dissolved oxygen on $\gamma$-PGA production during pellicle formation, a microaerated culture system (MACS), obtained by utilizing the microporous Teflon tube Poreflon (Sumitomo Electric Fine Polymer), was used (Fig. 5b). MACS enabled us to aerate the culture without visible air bubbling. It was found that when the MACS was adopted, the cells grew in the liquid phase for as long as $9 \mathrm{~h}$ without forming pellicles. This result is in contrast with the observation that the cells started to form a pellicle at $6 \mathrm{~h}$ after inoculation in a standing culture system, and almost no cells grew in the liquid phase thereafter (Fig. 5a). These observations indicate that oxygen depletion in standing culture is involved in the initial steps of floating biofilm formation by $B$. subtilis $\mathrm{B}-1$.

\section{Analysis of membrane proteins in the biofilm and planktonic cells}

In order to obtain further insight into the physiological difference between the biofilm and planktonic cells, membrane proteins prepared from the pellicles, planktonic cells and colonies were comparatively analysed by SDSPAGE, followed by Coomassie brilliant blue staining (Fig. 6). It was obvious that the protein profiles of biofilm and colony cells were simpler than those of planktonic cells. Proteins with sizes of 77 (P77), 57 (P57) and $36 \mathrm{kDa}$ (P36) were produced predominantly in the cells from pellicles and colonies when compared with planktonic cells. Analyses by Sequest, based on the partial amino acid sequences of these proteins, indicated that P77, P57 and P36 were a minor 

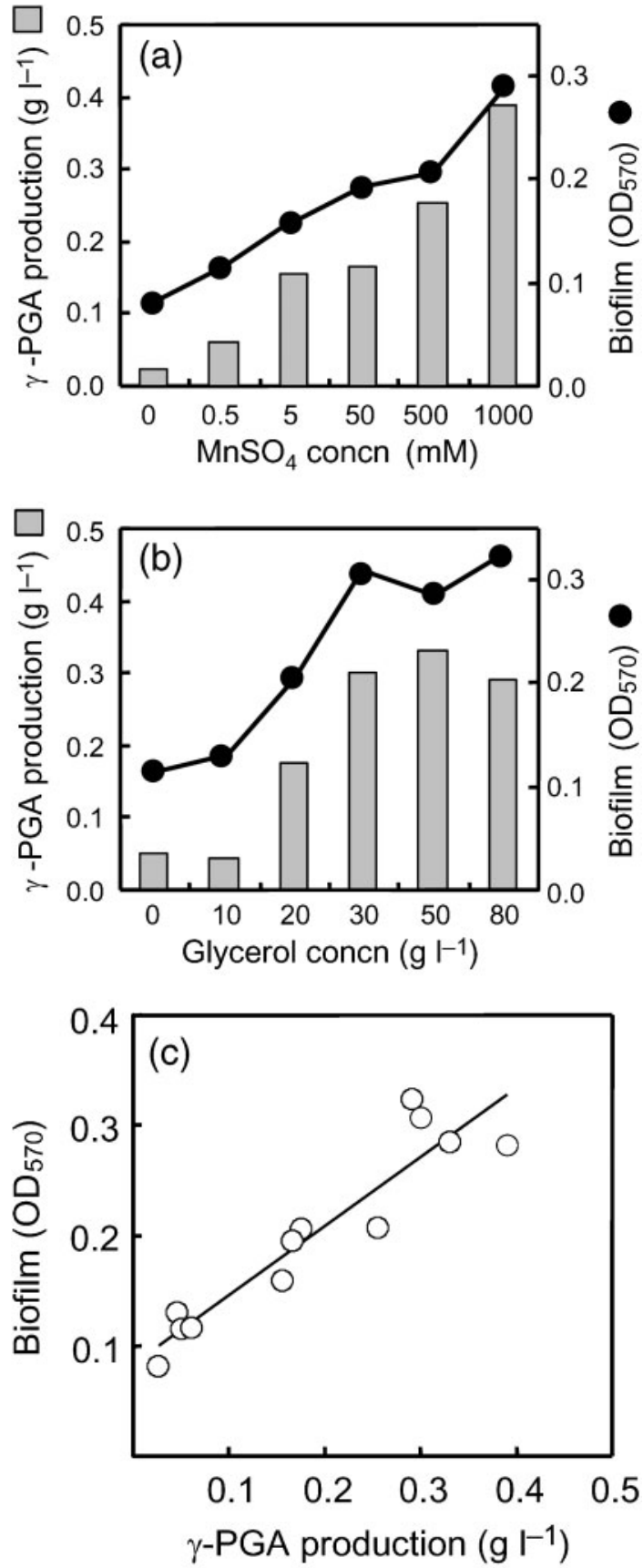

Fig. 3. Effects of $\mathrm{MnSO}_{4}$ and glycerol on $\gamma$-PGA production and biofilm formation. Bar and line graphs indicate $\gamma$-PGA production $\left(\mathrm{g}^{-1}\right)$ and amounts of biofilm $\left(\mathrm{OD}_{570}\right)$, respectively. Strain B-1 was grown in E-medium supplemented with $\mathrm{MnSO}_{4}$ (a) and glycerol (b) at $37^{\circ} \mathrm{C}$ for $8 \mathrm{~h}$. There was a direct correlation between $\gamma$-PGA production and biofilm formation for various $\mathrm{MnSO}_{4}$ and glycerol concentrations (c).

extracellular protease precursor (Vpr; P29141), an oligopeptide permease (OppA; CAA39787/Spo0K, AAA62687), and a mature flagellin (Hag; P02968), respectively. The ComX-ComP-ComA signalling pathway is a major quorum response pathway in $B$. subtilis, and it regulates the
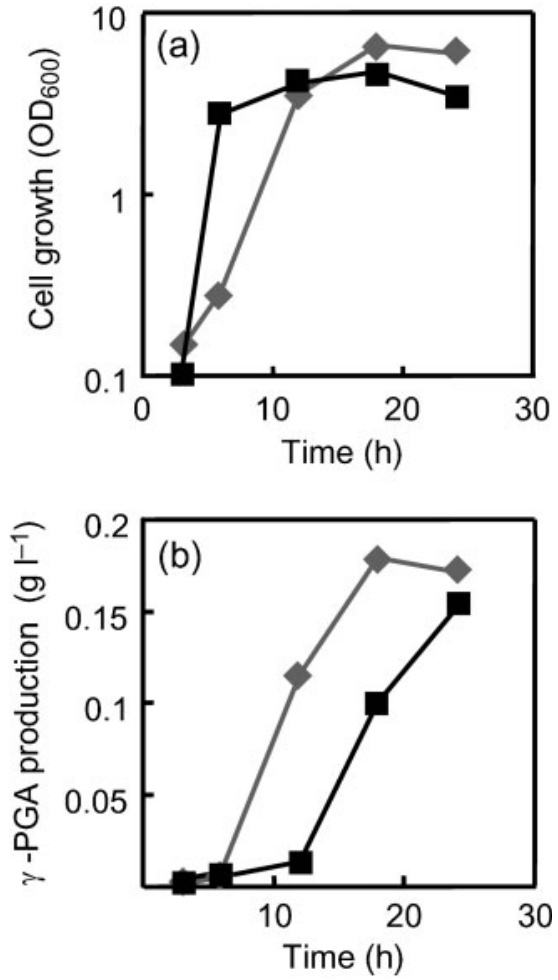

Fig. 4. Comparison of standing and shaking culture systems in terms of cell growth (a) and $\gamma$-PGA production (b). $\boldsymbol{\square}$, Shaking culture; standing culture. Cells were grown in L-broth at $37^{\circ} \mathrm{C}$.

production of $\gamma$-PGA (Comella \& Grossman, 2005; Stanley \& Lazazzerra, 2005). Accumulation of ComX pheromone stimulates the membrane histidine kinase ComP, resulting in autophosphorylation. Phosphorylated ComP donates the phosphate to the response regulator ComA, leading to activation of ComA-dependent promoters. CSF (competence-stimulating factor; derived from the $\mathrm{phrC}$ gene product) is another pheromone that stimulates ComA activity (Lazazzera, 2000). CSF inhibits RapC, which negatively regulates transcription of comA. CSF is produced from pro-CSF, after being processed by extracellular serine proteases such as Vpr, Epr and Apr (subtilisin E) (Lazzazerra, 2006). CSF is transported into the cell by an ATP-binding cassette $(\mathrm{ABC})$ transporter system containing oligopeptide permease (OppA/Spo0K). The observation that OppA/ Spo0K (P57) and Vpr precursor (P77) were predominantly expressed in the pellicle and colony samples suggests that a quorum-sensing system actively functions in these cells. It is interesting that P36 was found to be flagellin, and that it was significantly produced by the pellicle and the colony cells. Although Chagneau and Saier have demonstrated that flagella are required for biofilm formation, a DNA microarray analysis of $B$. subtilis biofilms has shown that the expression of genes encoding flagella is repressed (Chagneau \& Saier, 2004; Stanley et al., 2003). Another report has shown that there is no significant difference in the expression level of 

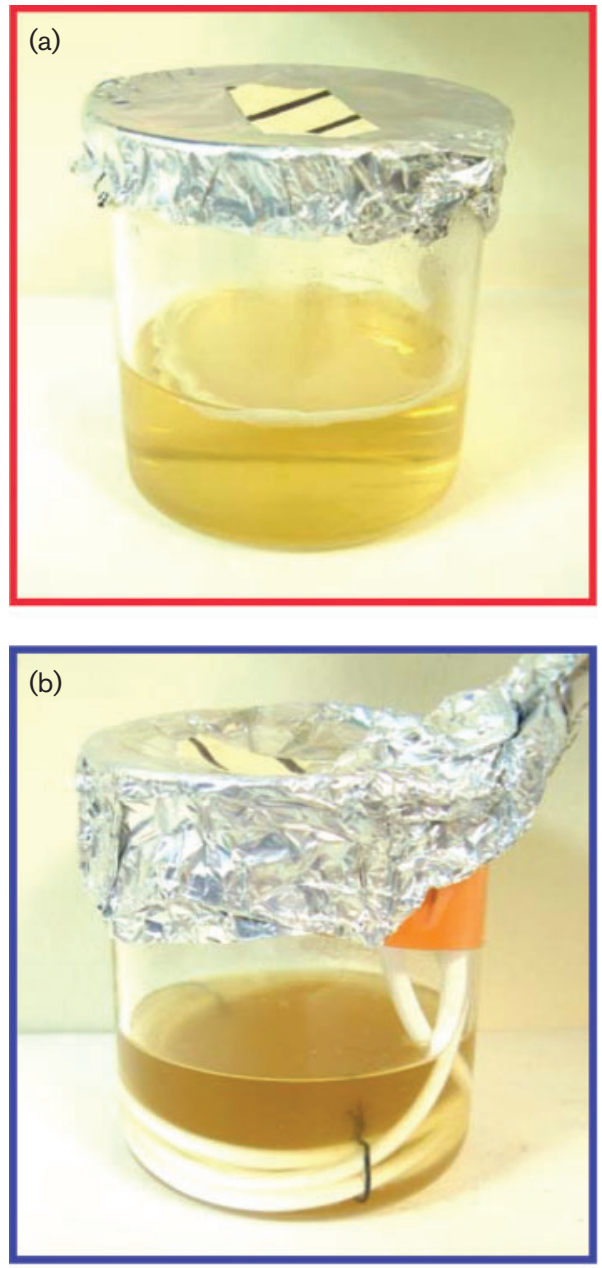

Fig. 5. Comparison of cell growth in standing culture (a) and MACS (b). Both culture vessels were placed at $37^{\circ} \mathrm{C}$ for $9 \mathrm{~h}$ without shaking.

the gene encoding flagellin in biofilm cells, when compared with planktonic cells (Ren et al., 2004). These contradictions remain to be explained. However, the existence of flagella in biofilm cells was also confirmed by electron microscopic observation after uranyl acetate staining (not shown). Our results may suggest that flagella in B-1 biofilm cells are produced for a purpose other than cell swimming. In the case of Aeromonas hydrophila $\mathrm{AH}-3$, production of lateral flagella has been shown to be specifically increased on semi-solid media and surfaces, and to be important for adherence and biofilm formation (Canals et al., 2006).

\section{ACKNOWLEDGEMENTS}

The authors are grateful to Professor M. Itaya (Keio University) for kindly providing B. subtilis natto BEST 195, and E. Oiki (Osaka University) for his excellent assistance in SEM observation. This work was supported by grants from the Institute for Fermentation, Osaka, and J-Power, to M. M., and the National Institutes of Health to R. K. (GM58213).

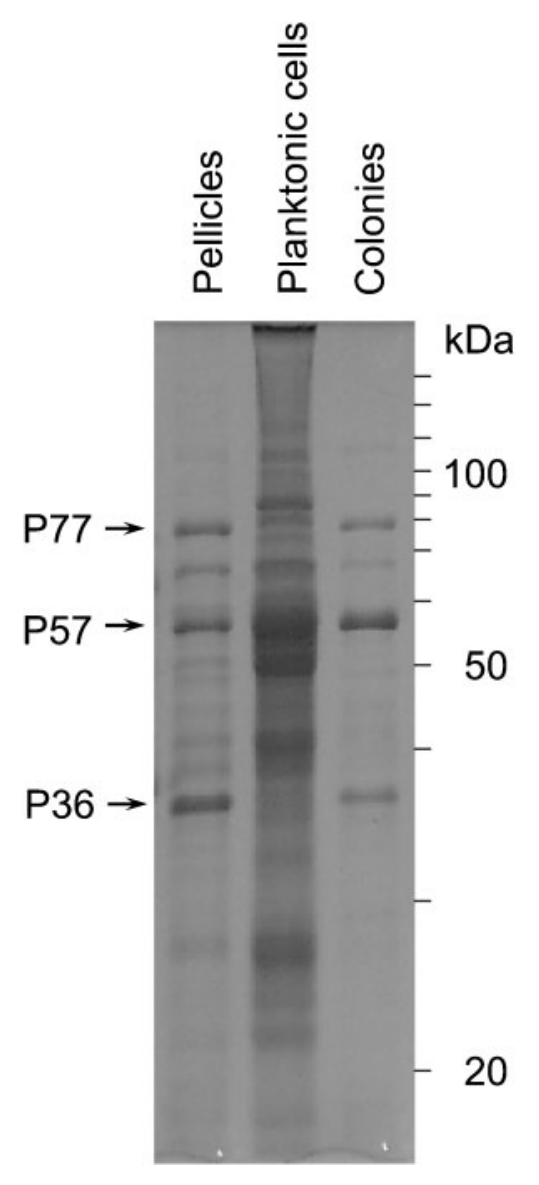

Fig. 6. Membrane protein analyses of B-1 cells from the floating biofilm (pellicles), shaking culture (planktonic cells) and colonies. Cells were grown at $37^{\circ} \mathrm{C}$ for $24 \mathrm{~h}$, with an inoculum size of $5 \%$.

\section{REFERENCES}

Boyd, A. \& Chakrabarty, A. M. (1995). Pseudomonas aeruginosa biofilms: role of the alginate exopolysaccharide. J Ind Microbiol 15, 162-168.

Branda, S. S., Gonzalez-Pastor, J. E., Ben-Yehuda, S., Losick, R. \& Kolter, R. (2001). Fruiting body formation by Bacillus subtilis. Proc Natl Acad Sci U S A 98, 11621-11626.

Branda, S. S., Vik, S. L., Friedman, L. \& Kolter, R. (2005). Biofilms: the matrix revisited. Trends Microbiol 13, 20-26.

Canals, R., Altarriba, M., Vilches, S., Horsburgh, G., Shaw, J. G., Tomas, J. M. \& Merino, S. (2006). Analysis of the lateral flagellar gene system of Aeromonas hydrophila AH-3. J Bacteriol 188, 852-862.

Chagneau, C. \& Saier, M. H., Jr (2004). Biofilm-defective mutants of Bacillus subtilis. J Mol Microbiol Biotechnol 8, 177-188.

Comella, N. \& Grossman, A. D. (2005). Conservation of genes and processes controlled by the quorum response in bacteria: characterization of genes contolled by the quorum-sensing transcription factor ComA in Bacillus subtilis. Mol Microbiol 57, 1159-1174.

Cromwick, A. M. \& Gross, R. A. (1995). Effects of manganese (II) on Bacillus licheniformis ATCC 9945A physiology and gamma-poly (glutamic acid) formation. Int J Biol Macromol 17, 259-267. 
Cromwick, A.-M., Birrer, G. A. \& Gross, R. A. (1996). Effects of pH and aeration on $\gamma$-poly (glutamic acid) formation by Bacillus licheniformis in controlled batch fermentor cultures. Biotechnol Bioeng 50, 222-227.

Danese, P. N., Pratt, L. A. \& Kolter, R. (2000). Exopolysaccharide production is required for development of Escherichia coli K-12 biofilm architecture. J Bacteriol 182, 3593-3596.

Friedman, L. \& Kolter, R. (2004). Two genetic loci produce distinct carbohydrate-rich structural components of the Pseudomonas aeruginosa biofilm matrix. J Bacteriol 186, 4457-4465.

Glauert, A. M. (1975). Fixation, dehydration, and embedding of biological specimens. In Practical Methods in Electron Microscopy. Edited by A. M. Glauert. Amsterdam: North Holland.

Hamon, M. A. \& Lazazzera, B. A. (2001). The sporulation transcription factor Spo0A is required for biofilm development in Bacillus subtilis. Mol Microbiol 42, 1199-1209.

Itaya, M. \& Matsui, K. (1999). Conversion of Bacillus subtilis 168: Natto producing Bacillus subtilis with mosaic genomes. Biosci Biotechnol Biochem 63, 2034-2037.

Kearns, D. B., Chu, F., Branda, S. S., Kolter, R. \& Losick, R. (2005) A master regulator for biofilm formation by Bacillus subtilis. Mol Microbiol 55, 739-749.

Kiska, D. L. \& Macrina, F. L. (1994). Genetic analysis of fructanhyperproducing strains of Streptococcus mutans. Infect Immun 62, 2679-2686.

Ko, Y. H. \& Gross, R. A. (1998). Effects of glucose and glycerol on gamma-poly(glutamic acid) formation by Bacillus licheniformis ATCC 9945a. Biotechnol Bioeng 57, 430-437.

Lazazzera, B. A. (2000). Quorum sensing and starvation: signals for entry into stationary phase. Curr Opin Microbiol 3, 177-182.

Lazazzera, B. A. (2006). Production of Peptide Signaling Molecules by Bacillus subtilis. Presentation at the 106th American Society for Microbiology meeting, May 24 2006, Orlando, FL. Washington, DC: American Society for Microbiology.

May, T. B. \& Chakrabarty, A. M. (1994). Isolation and assay of Pseudomonas aeruginosa alginate. Methods Enzymol 235, 295-304.
Morikawa, M., Ito, M. \& Imanaka, T. (1992). Isolation of a new surfactin producer Bacillus pumilus A-1, and cloning and nucleotide sequence of the regulator gene, psf-1. J Ferment Bioeng 74, 255-261.

O'Neill, M. A., Morris, V. J., Selvendran, R. R., Sutherland, I. W. \& Taylor, I. T. (1986). Structure of the extracellular gelling polysaccharide produced by Enterobacter (NCIB 11870) species. Carbohydr Res 148, 63-69.

O’Toole, G. A., Pratt, L. A., Watnick, P. I., Newman, D. K., Weaver, V. B. \& Kolter, R. (1999). Genetic approaches to study of biofilms. Methods Enzymol 310, 91-109.

O'Toole, G., Kaplan, H. B. \& Kolter, R. (2000). Biofilm formation as microbial development. Annu Rev Microbiol 54, 49-79.

Parsek, M. R. \& Greenberg, E. P. (2005). Sociomicrobiology: the connections between quorum sensing and biofilms. Trends Microbiol 13, 27-33.

Ren, D., Bedzyk, L. A., Setlow, P., Thomas, S. M., Ye, R. W. \& Wood, T. K. (2004). Gene expression in Bacillus subtilis surface biofilms with and without sporulation and the importance of $y v e R$ for biofilm maintenance. Biotechnol Bioeng 86, 344-364.

Stanley, N. R. \& Lazazzera, B. A. (2005). Defining the genetic differences between wild and domestic strains of Bacillus subtilis that affect poly-gamma- DL-glutamic acid production and biofilm formation. Mol Microbiol 57, 1143-1158.

Stanley, N. R., Britton, R. A., Grossman, A. D. \& Lazazzera, B. A. (2003). Identification of catabolite repression as a physiological regulator of biofilm formation by Bacillus subtilis by use of DNA microarrays. J Bacteriol 185, 1951-1957.

Wai, S. N., Mizunoe, Y., Takade, A., Kawabata, S. I. \& Yoshida, S. I. (1998). Vibrio cholerae O1 strain TSI-4 produces the exopolysaccharide materials that determine colony morphology, stress resistance, and biofilm formation. Appl Environ Microbiol 64, 3648-3655.

Yamazaki, M., Thorne, L., Mikolajczak, M., Armentrout, R. W. \& Pollock, T. J. (1996). Linkage of genes essential for synthesis of a polysaccharide capsule in Sphingomonas strain S88. J Bacteriol 178, 2676-2687. 